\title{
Horses for courses: Fund managers and organizational structures*
}

\author{
Yufeng Han, Tom Noe, and Michael Rebello ${ }^{\dagger}$
}

February, 2016

*The authors wish to thank Janis Berzins, Bartley Danielsen, Jie Gan, Karlyn Mitchell, Richard Warr, Kelsey Wei, Anthony Saunders (the editor), an anonymous referee, and seminar participants at North Carolina State University, University of Colorado Denver, ISCTE Business School - Nova Annual Finance Conference - Mutual Funds and Investment Management, Second Singapore International Conference on Finance, Second Luxembourg Asset Management Summit, and Southern Finance Association Annual Meetings for helpful comments and Susan Bergman for editorial help.

†Yufeng Han is at The Business School, University of Colorado Denver, Denver, CO 80217. Phone: (303)315-8458 and email: yufeng.han@ucdenver.edu. Tom Noe is at Saïd Business School, University of Oxford, Oxford, OX1 1HP, UK. Phone: 44(0)1865 288933 and email: thomas.noe@sbs.ox.ac.uk. Michael Rebello is at School of Management, University of Texas at Dallas, Richardson, TX 75080. Phone (972) 883-5807 and email:mjr071000@utdallas.edu. 


\title{
Horses for courses: Fund managers and organizational structures
}

\begin{abstract}
We model and test the relations between the team management of mutual funds, managers' ability, performance, and holdings. Our model predicts that team-managed funds perform better and behave more conservatively than single-manager funds. However, the effect of team-management is masked in equilibrium since high ability managers rationally self-select into single-manager funds. Consistent with the model's prediction, we find that team-managed funds perform better and deviate less from their benchmark allocations than single-manager funds with the same characteristics. These differences are marked after we control for the endogenous self-selection of managers.
\end{abstract}




\section{Introduction}

The number of team-managed funds is rapidly increasing and these funds have also experienced a surge in inflows. ${ }^{1}$ The growing popularity of team-managed funds has prompted researchers to examine the source of their appeal to investors (see, e.g., Bär, Kempf, and Ruenzi, 2010; Bliss, Potter, and Schwarz, 2008). These researchers have documented differences in the characteristics of team-managed and single-managed funds. Some have found that team-managed funds perform no differently than single-managed funds (Bliss et al., 2008), while others have found that they underperform single-managed funds (Bär et al., 2010; Massa, Reuter, and Zitzewitz, 2010; Chen, Hong, Huang, and Kubik, 2004). The inability of researchers to uncover evidence that team-managed funds outperform singlemanaged funds raises an obvious question: Why is the reliance on team-managed mutual funds growing relative to apparently better performing single-manager funds?

To answer to this question, we formally model the employment choices of fund managers who are privately informed about their abilities. In our model, in equilibrium, based on their abilities, managers rationally and endogenously select into funds with different organizational designs: high-ability managers opt for single management while low-ability managers opt for team management. As a consequence of this self-selection, funds managed by a single manager outperform team-managed funds even when the single management design is inferior to team management. The superiority of the team management design is masked because managerial ability is not observable. We test these and other predictions of our model and examine the effect of managerial self-selection using a comprehensive sample of mutual funds.

In our model, absent any private information, deviating from a fund's benchmark allocation hurts its performance. However, fund managers receive noisy signals which are correlated with the gains from deviation from the benchmark. After receiving a positive signal regarding the expected gain from deviation, deviation may be optimal. However, some positive signals are irrelevant "red herrings" and contain no information about future

\footnotetext{
${ }^{1}$ For example, in 2007, Fidelity Investments recently switched its marketing strategy to emphasize its team-managed funds (Reuters, 2007).
} 
returns. Trading on red herring signals results in expected losses from deviation. Team management permits information pooling which helps funds distinguish red herrings from relevant signals. ${ }^{2}$ Thus, the team management structure, by permitting funds to weed out unreliable signals, lowers the likelihood a fund will deviate from its benchmark allocation. For the same reason it increases the fund's expected return conditioned on deviation from its benchmark. However, team formation imposes costs on managers. Joining a team dilutes managers' rewards from outperforming the fund's benchmark. ${ }^{3}$ High-ability managers, who receive higher quality signals, gain less from the information pooling effect of team management. The tension between these forces leads to equilibria in which only low-ability managers choose to join teams. For high-ability managers, the incremental improvement in fund returns generated by team membership is not sufficient to offset the reward-dilution effect of the team structure. As a result of this self-selection, fund performance is driven by both organizational design and (unobserved) managerial ability. Therefore, when the ability gap between high and low-ability managers is large, even though the team management structure facilitates better performance by improving information quality and thus, fund performance, the self-selection leads single-managed funds to outperform team-managed funds.

The model's predictions regarding fund performance and asset allocations follow directly from the theory: Fund performance is driven by both organizational design and (unobserved) managerial ability. When the ability gap between high and low-ability managers is large, even though the team management structure facilitates better performance by improving information quality and thus, fund performance, self-selection leads single-managed funds to outperform team-managed funds. Fund allocations are also jointly determined by fund

\footnotetext{
${ }^{2} \mathrm{~A}$ number of papers have modeled and documented the positive effects of forming teams. Gomes and Novaes (2006) show, conflicts between self-interested agents can lead to policies that more closely approximate the common good. A number of empirical studies such as Hill (1982); Blinder and Morgan (2001); Bone, Hey, and Suckling (1999); Pelled, Eisenhardt, and Xin (1999), show that teams perform better than individuals. Sharpe (1981) shows that team management may offer benefits from specialization of team members and diversification among managers. Barry and Starks (1984) argue that team management offers benefits from reducing the agency problem between investors and managers.

${ }^{3}$ This is the logic underlying the argument in Massa et al. (2010) that families adopt the team management structure to limit the employment options of fund managers.
} 
management structure and managerial ability. Because team management weeds out trades based on unreliable signals, it lowers the likelihood that funds will deviate from the benchmark. As with performance, the equilibrium self-selection of high-ability managers into single-managed funds can mask the influence of team management.

We find empirical support for these predictions. We regress fund performance, measured by the CAPM, Carhart four-factor, and Fama-French models, and benchmark deviations, measured by normalized squared difference between fund allocations and style-based benchmark allocations, on management structure. After controlling for selection bias, we find that team-managed funds produce higher alphas and deviate less from their benchmark allocations. Team management's effect is economically significant. In several of our regressions, we estimate that team management would on average increase expected risk-adjusted abnormal returns by over one percent per annum. Consistent with our predictions, the self-selection of fund managers weakens these relations.

The difficulty of measuring managerial ability generates a latent variable problem, which we confront with several econometric techniques. Specifically, we employ Instrumental Variable (IV), Control Function (CF), and Heckman Correction (HK) approaches. Estimates based on these approaches uniformly support our prediction that team management is the superior structure. To further validate our results, using an approach developed in Ashley (2009), we perform a sensitivity analysis of the robustness of our IV regressions to violations of the exclusion restriction. We find that the correlation between the instrument and the error term would have to be more than twice the correlation between the error term and organizational structure itself for violations of the exclusion restriction to generate statistically insignificant $p$-values in the absence of any true relationship between team management and performance. We also find support for our predictions when we examine a quasi-natural experiment where families make wholesale changes to the organizations of their funds.

Our basic approach to explaining the differences between team and single-managed mutual funds is not novel. A key assumption behind our analysis (and many other papers on 
mutual fund manager behavior) is that some managers are able to create value by following unobserved trading strategies in individual stocks. This assumption is validated by the research of Kacperczyk, Sialm, and Zheng (2005). Moreover, ours is not the first paper to consider the perplexing rush into team-managed funds despite the lack of any documented performance advantage for team management. Both Bär et al. (2010) and Bliss et al. (2008) have considered this issue. Massa et al. (2010) have even recognized that managers may prefer a single-manager structure. Our point of departure is to attempt to explain the rush toward team management as rational response to the superior performance characteristics of team management, characteristics which are masked by selection bias.

\section{Model}

Consider a single-period world populated by a perfectly elastic supply of investors who invest their capital in mutual funds. Funds are managed by fund "families" which are also in perfectly elastic supply. Families determine whether each of their funds will be managed by a single manager or a team. Managers, who are privately informed about their abilities, selfselect into fund organization structures. We assume that families as well as outside investors have no private information regarding managerial ability. This assumption abstracts from the ability of families to acquire private information about managerial ability (Gervais, Lynch, and Musto, 2005). Provided fund information about managerial ability is imperfect, our basic results are robust to fund-family learning. ${ }^{4}$ Managers determine fund performance

\footnotetext{
${ }^{4}$ Introducing fund-family learning is an interesting direction for extending our analysis but would greatly complicate it. In a model in which families are better informed about their managers' abilities than outside investors, a manager's termination or separation from a fund family would be informative to outsiders and thus affect the manager's ability to subsequently attract capital and fee income. Hence, families would be able to extract rents from their managers through capturing a fraction of the fees charged by the fund. Because of fund-family bargaining power, fund structure would be negotiated between families and managers. The resulting model would be a complex asymmetric information bargaining game whose solution would depend on off-equilibrium conjectures about the information effect of manager exit from a fund family. However, in this setting, it would still be the case that high-ability managers (i.e., managers with ability in excess of their funds' estimate of their ability) would gain more than low-ability managers from the single-manager structure. Thus, if, despite learning, fund managers still had better information about their ability than families, families would aim to capture rents from high ability managers through offering to permit them to single manage funds in exchange a larger fraction of management fees for the family. Terms would exists at which high-ability managers would accept and low ability managers would reject such offers. Hence, ability
} 
through their asset allocation decisions. Management compensation is endogenous and is an outcome of the equilibrium that matches managers to fund organizational structures.

A fund family can require a fund to be passive and mimic a benchmark index or permit the fund to be active, i.e., to possibly deviate from the benchmark. ${ }^{5}$ Each fund family adopts the same organizational structure for all its actively managed funds: either it requires each actively managed fund to be managed by a single manager or it puts in place a team of two managers for each fund. ${ }^{6}$ Each fund is capitalized with one dollar for each of its managers; the lone manager of a fund organized as a single-managed fund, whom we shall term a "single manager" has one dollar of capital and the managers of a team-managed fund collectively have two dollars of capital. ${ }^{7}$ While each team-managed fund manages two dollars of capital, to limit the complexity of our notation and to keep the analysis transparent, we focus on the return per dollar of capital invested in each team-managed fund. As will become clear in the following analysis, our results are unaffected if instead, we focus on the return on the entire capital invested in each team-managed fund.

Fund families have to recruit managers for every actively-managed fund in their stable. These hiring decisions are made at the beginning of the period. A fund's managers receive a fraction $\alpha \in(0,1]$, of its returns. ${ }^{8}$ This fraction is endogenously determined based on

selection based on unobservable attributes into single management would still occur.

${ }^{5}$ Like Berk and Green (2004), we assume that competition between investors ensures that fund managers capture all rents from skill through their fees. As in Berk and Green (2004), investors bid up the fees they are willing to pay to the point where the marginal investor is indifferent between buying the index or a skill-based fund. Because fees are non-negative, a skill-based fund in our model must provide expected returns at least equal to the index. Thus, for a fund to be viable, the costs of skill-based management induced by incentive distortion must be at least offset by the performance alpha generated through skill. When investors believe that, under a given management structure, fund managers cannot meet this hurdle, the fund family will be unable to launch a skill-based fund using these managers and management structure. By the same logic, when a fund family restricts a fund to mimic the index, because the fund will not generate excess returns, the fund will only be viable if its managers do not receive any rents, i.e., only managers of funds that can deviate from their benchmark receive any rents in equilibrium

${ }^{6}$ This assumption is consistent with evidence that funds in a fund family tend to maintain the same organizational structure (Bär et al., 2010).

${ }^{7}$ Our evidence is consistent with this assumption; team-managed funds are significantly larger than single-managed funds.

${ }^{8}$ This assumption is made without any loss of generality since in all equilibria we characterize, managers' asset allocation decisions cannot be improved upon by changing the structure of their compensation contracts. 
investor expectations. When the fund is managed by a team, and the team is managed by managers of equal ability, we assume that both managers receive equal payoffs. ${ }^{9}$

After each fund recruits its management, the management allocates the fund's assets. Management can either mimic the benchmark index or choose a radically different "deviant" asset allocation. For convenience, we refer to the benchmark-mimicking allocation as a "safe" allocation and the deviant allocation as a "risky" allocation. If a manager has sole charge of a fund, he has complete authority over the allocation. A team can only choose the risky allocation if both managers support the choice. The risky allocation generates a random return: Following a "good" outcome, $G$, the return per invested dollar is $1+r>1$, but following a "bad" outcome, $B$, the return is $1-r-\lambda<1$, where $\lambda>0$. The prior probability of the good outcome, $G$, is $\pi<1 / 2$. This assumption captures that notion that deviating from the benchmark allocation will typically not generate superior fund performance. Regardless of the outcome, the safe allocation generates a return of one dollar per invested dollar. ${ }^{10}$

Managers receive a private benefit if their fund is successful, i.e., the fund generates the return $1+r{ }^{11}$ This benefit is $\mathcal{B}$ when the manager has sole charge of a fund. When the fund is managed by a team, each team member gets a private benefit of $\delta \mathcal{B}$, where $\delta<1$. One reason team members receive smaller private benefits is that it is more difficult, at least for outsiders, to attribute the fund's success to a particular team member. ${ }^{12}$ All managers, investors, and families know of the structure of managerial private benefits.

Before the fund makes its asset allocation decision, each manager receives a private signal. The signal realization, $\sigma$, is drawn from the set $\{g, b\}$. Either all managers receive

\footnotetext{
${ }^{9}$ We only consider equilibria in which managers of equal ability are matched. We show that these equilibria are stable in the sense that there do not exist any sharing rules which will induce paired managers to defect to heterogeneous teams in which both team members gain from defection.

${ }^{10}$ Our results are not driven by this assumption. What is important from our model's perspective is that (a) the deviant allocation generates a lower return ex ante than the benchmark allocation and (b) the manager's private information relates to the deviant allocation.

${ }^{11}$ This private benefit can be viewed as a reduced-form representation of the benefits managers receive when their funds outperform their benchmarks. These rewards include increased fund fees resulting from fund inflows and more lucrative employment (Massa et al., 2010).

${ }^{12}$ There is an extensive literature on the performance of teams when the contributions of individual team members cannot be observed (see, e.g., (Alchian and Demsetz, 1972)).
} 
uninformative signals, $\mathbb{U}$, or they all receive informative ones, $\mathbb{I}$. Let the signal's informativeness, i.e., the signal's type, be represented by $T$, where $T \in\{\mathbb{U}, \mathbb{I}\}$. Managers do not know the signal's type. The common prior that nature will generate uninformative signals is $v$. Each uninformative signal is independent of the outcome and independent of every other uninformative signal. Therefore, uninformative signals have the following distribution:

$$
\operatorname{Prob}[\sigma=g \mid O=G \& T=\mathbb{U}]=\operatorname{Prob}[\sigma=g \mid O=B \& T=\mathbb{U}]=\pi,
$$

where $O$ denotes the outcome, $G$ or $B$. In contrast, informative signals are correlated with the outcome and, when managers belong to a team, their signals are perfectly correlated, i.e., when the signal is informative, if one member of a team observes the signal $b(g)$ so does the other member. Informative signals have the following distribution:

$$
\begin{aligned}
& \operatorname{Prob}[\sigma=g \mid O=G, T=\mathbb{I}]=\mu, \operatorname{Prob}[\sigma=b \mid O=G, T=\mathbb{I}]=1-\mu, \\
& \operatorname{Prob}[\sigma=b \mid O=B, T=\mathbb{I}]=\mu, \operatorname{Prob}[\sigma=g \mid O=B, T=\mathbb{I}]=1-\mu,
\end{aligned}
$$

where $\mu$ captures the precision of the informative signal. The precision of an individual manager's informative signal varies his ability and the organizational structure of his fund. A manager can either have high ability, $H$, or low ability, $L$. Each manager knows his ability (type), $t \in\{H, L\}$. However, his type is not known by the other agents, all of whom have a common prior that a manager is type $H$ with probability $\theta \in(0,1)$. The assumption that managers know their type is not essential to produce the results in this paper but it simplifies the analysis. What is required is that managers have better information about their personal ability than both investors and families. ${ }^{13}$

A fund's management structure is determined by the number of managers it employs and the abilities of the managers; the subscript $L(H)$ indicates that the fund has only

\footnotetext{
${ }^{13}$ Assuming that managers observe an informative but imperfect signal of their type would have no material effect on our results except to make the algebra more messy. In this alternative framework, fund managers would receive two imperfect private signals: one signal of asset value and one signal of ability. The managers' expected returns from the single-managed structure and the team managed structure would be a signal-conditioned mixture of returns from high and low ability. It would still be the case that managers whose informative signal about ability produced a higher likelihood of high ability would expect larger gains from single management relative to team management than managers receiving signals that produced a lower likelihood of high ability. As in our model, these differential gains would support separation and selection of managers with positive ability signals into single-management.
} 
one manager whose type is $L(H)$. Similarly, the subscripts $L L, L H$ and $H H$ indicate management by a team of two type $L$ managers, a team of one type $L$ and one type $H$ manager, and a team of two type $H$ managers, respectively.

We assume that the following ordering for the precision of the managers' signals:

$$
\frac{1}{2}<\mu_{L}<\mu_{L L}<\mu_{H}<\mu_{L H}<\mu_{H H}
$$

This ordering ensures that informative signals are, in fact informative, signal precision improves with managerial ability, signal precision for team-managed fund improves with the average ability, signal precision increases with the number of fund managers, and the signal precision for a single high-ability manager is higher than the signal precision for team consisting of two low-ability managers.

Our information structure as a stylized representation of a world where fund managers receive a stream of rumors about the payoff from benchmark deviation. Some of these rumors represent real information about prospective returns, other rumors are irrelevant "red herrings." Fund managers cannot perfectly distinguish between relevant and irrelevant rumors. Increasing managerial ability and joining managers through team formation increases the ability of managers to extract information from relevant rumors.

Let the functions $R_{\pi}$ and $R^{I}(x)$ be defined as follows:

$$
\begin{aligned}
R_{\pi} & =\pi r-(1-\pi)(r+\lambda), \\
R^{I}(x) & =\pi x r-(1-\pi)(1-x)(r+\lambda) .
\end{aligned}
$$

Note that $1+R_{\pi}$ is the expected payoff from the risky allocation when evaluated using the prior probabilities of the outcomes. Also note that $R^{I}(x)$ is a monotone increasing function of $x$. To render our analysis meaningful by focusing it on an interesting subset of the parameter space, we assume that

$$
R^{I}\left(\mu_{L}\right)<0<\pi v R_{\pi}+R^{I}\left(\mu_{L L}\right)
$$

Since the signal precision $\mu_{L}>\frac{1}{2}>\pi$, Assumption (6) ensures that $0>R^{I}\left(\mu_{L}\right)>R_{\pi}$. Therefore, $1+R_{\pi}<1$. This implies that a fund cannot expect to outperform its bench- 
mark if it implements the risky allocation based only on prior information. By restricting $R^{I}\left(\mu_{L}\right)<0$, the assumption also ensures that a fund managed by a low-ability manager will underperform its benchmark. By restricting $0<\pi v R_{\pi}+R^{I}\left(\mu_{L L}\right)$, we ensure active management has value. Specifically, the precision of the information received by the lowest ability management team is sufficiently high to ensure that it has the ability to outperform its benchmark. When combined with Assumption (3), this condition also ensures that active management is attractive if the fund is managed by a single high-ability manager.

\section{A Equilibrium allocation}

Managers can only expect the safe allocation to outperform the risky allocation when their posterior probability of outcome $G$ is relatively low. However, since managers receive private benefits only when their fund outperforms the safe allocation, they may be willing to implement the risky allocation even when their posterior assessments of outcome $G$ are relatively low. In the extreme case, when manager's private benefits from outperforming the safe allocation are sufficiently high, they will implement the risky allocation even after the receipt of the signal $b$. The next result, Lemma 1 , shows that when managerial private benefits are so high that managers will implement the risky allocation regardless of their information signals, funds cannot attract investor capital and thus managers cannot signal their ability with their employment choices.

Lemma 1. No fully revealing separating equilibrium exists in which A. A manager with sole charge of a fund selects the risky allocation after receiving the signal b. B. A team of managers selects the risky allocation after they both receive the signal b.

Lemma 1 establishes that there cannot exist separating equilibria where funds implement the risky allocation even after management's information indicates that the bad outcome is likely. However, it is possible that, off the equilibrium path, managers may choose the risky allocation even after their information indicates that the bad outcome is likely. This greatly complicates the analysis. Therefore, in the interest of simplifying the exposition and avoiding 
unnecessary complication, without loss of generality, we make the following assumption:

$$
R_{\pi}+\pi \mathcal{B}<0
$$

As we demonstrate below, assumption (7) ensures that managers never choose the risky allocation after they receive the signal $b$.

Lemma 2. When (7) is satisfied, A. A manager with sole charge of a fund will never implement the risky allocation after receiving the signal $b$. B. A team of managers will never implement the risky allocation after one of them receives the signal $b$.

Let $R_{U}^{S}\left(R_{U}^{T}\right)$ represent the expected return from implementing the risky allocation when the signal in uninformative, the fund is single-managed (team managed), and the fund makes the risky allocation if and only if the signal equals $g$. Because, uninformative signals are independent of the state and each other, and because the expected gain conditioned on the risky allocation under the uninformative signal is $R_{\pi}, R_{U}^{S}$ and $R_{U}^{T}$ are given by

$$
R_{U}^{S}=\pi R_{\pi} \quad R_{U}^{T}=\pi^{2} R_{\pi}
$$

From Lemma 2 it is clear that investors will expect a single-managed fund to implement the risky allocation only after the manager observes the signal $g$. Therefore, investors will expect a single-managed fund whose manager receives a signal with precision $\mu$ to generate an expected payoff of

$$
1+v R_{S}^{U}+(1-v) R^{I}(\mu)
$$

Since there is a perfectly elastic supply of capital, fund managers will be able to capture any rents they generate. Hence, when investors invest in a fund run by a single manager with a signal precision of $\mu$, they will demand the fraction $1-\alpha_{S}(\mu)$ of the fund's expected payoff, where

$$
1=\left(1-\alpha_{S}(\mu)\right)\left(1+v R_{S}^{U}+(1-v) R^{I}(\mu)\right) \Rightarrow \alpha_{S}(\mu)=\frac{v R_{S}^{U}+(1-v) R^{I}(\mu)}{1+v R_{S}^{U}+(1-v) R^{I}(\mu)} .
$$

From Lemma 2, investors will expect a team-managed fund to implement the risky allocation only after both managers observes the signal $g$. Therefore, investors will expect a 
team-managed fund whose managers' signal precision is $\mu$ to generate an expected payoff of

$$
\begin{array}{r}
\pi\left(v \pi^{2}+(1-v) \mu\right](1+r)+(1-\pi)\left[v \pi^{2}+(1-v)(1-\mu)\right)(1-r-\lambda)= \\
1+v R_{T}^{U}+(1-v) R^{I}(\mu) .
\end{array}
$$

Once again, since there is a perfectly elastic supply of capital, it follows that, when investors invest in a fund managed by a team with a signal precisions of $\mu$, they will demand the fraction $1-\alpha_{T}(\mu)$ of the fund's expected payoff, where

$$
1=\left(1-\alpha_{T}(\mu)\right)\left(1+v R_{T}^{U}+(1-v) R^{I}(\mu)\right) \Rightarrow \alpha_{T}(\mu)=\frac{v R_{T}^{U}+(1-v) R^{I}(\mu)}{1+v R_{T}^{U}+(1-v) R^{I}(\mu)} .
$$

Thus, holding private benefits constant, managers' payoffs depend on (a) fund performance, measured by $R$, and (b) the fraction of performance gains they capture, measured by $\alpha$.

\section{B Fully-revealing separating-equilibria}

We now establish the existence of equilibria in which managers' employment choices signal their abilities, i.e., where all managers of a given type opt for the same fund structure. We call these equilibria "fully-revealing separating equilibria." We focus on these equilibria since they provide clear predictions relating fund management structure to fund performance and allocations. Moreover, they highlight the effect of managerial self-selection on tests of the relation between fund management structure and fund performance or fund allocations.

There are two possible types of fully-revealing separating equilibrium outcomes: either low-ability managers opt to work for single-managed funds and high-ability managers for team-managed funds or vice versa. In the following proposition, we establish that there cannot exist a separating equilibrium in which low-ability managers work for single-managed funds and high-ability managers for team-managed ones. The intuition behind this result is straightforward. The precision of the signals received by low-ability managers is not high enough for them to implement asset allocations that can outperform the safe allocation. Therefore, such funds will not be able to attract investor capital, and thus, no fund family will have active funds managed by a single low-ability manager. 
Proposition 1. There cannot exist a fully revealing separating equilibrium in which actively managed single-managed funds are run by low-ability managers.

In contrast to low-ability managers, high-ability managers may opt into single management structures. In the following proposition, we establish that there exist separating equilibria where this is indeed the case. These separating equilibria exist because managers trade off the improved allocation decisions from joining a team against the dilution of their private benefits from doing so. Because the marginal improvement in allocation decisions engendered by team is higher for low-ability managers, low-ability managers do not want to mimic high-ability manager's and opt into single-manager structures.

Proposition 2. There exist model parameters under which a fully revealing separating equilibrium exists in which single-managed funds are only run by high-ability managers and team-managed funds by low-ability managers.

\section{Equilibrium excess returns}

For a fixed fund structure, a fund's expected excess return will increase with the precision of the fund managers' information and thus with managerial ability. Because increasing the number of fund managers both increases the precision of informative signals and leads to better detection of uninformative signals, for a fixed level of managerial ability, team managed funds outperform single-managed funds. These results are formalized in Proposition 3.

Proposition 3. In any fully revealing separating equilibrium, A. For a fixed fund structure, a fund's expected excess return is increasing in managerial quality. B. For a fixed level of managerial ability, a fund's expected excess return is higher under team management.

Proposition 3 establishes that the team structure, ceteris paribus, leads to a higher excess return. However, in the fully revealing separating equilibrium, the high-ability managers selfselect into the less efficient single-manager structure. This self-selection effect may lead to higher observed returns for single-managed funds. This reversal will occur when the average difference in manager ability favoring single-managed funds swamps the direct benefit of 
using the team structure.

\section{Equilibrium allocations}

Both signal precision and fund structure affect equilibrium asset allocations. Since ex ante deviations from the benchmark allocation generate expected losses, managers with more precise information signals, measured by $\mu$, deviate less on average. In essence, the fact that on average the a manager will not be able to beat the benchmark implies that deviating to the risky allocation based on a false positive signal is more likely than not deviating to the risky allocation because of a false negative signal. Thus, as signal quality increases deviations from the benchmark fall. Fund structure also matters. Combining managers in a team increases signal precisions and also raises the likelihood that the managers will detect an uninformative signal and thus, avoid making the risky allocation without (useful) information. These observations are formalized in Proposition 4.

Proposition 4. In any fully revealing separating equilibrium, A. For a fixed fund structure, a fund's likelihood of implementing the risky allocation is decreasing with managerial ability. B. For a fixed level of managerial ability, a fund's likelihood of implementing the risky allocation is lower if it is team managed.

Proposition 4 establishes that, holding ability constant, the team structure lowers the likelihood of implementing the risky allocation. However, under self-selection ability is not held constant. High-ability managers self-select into single manager structures, a structure which leads to a higher likelihood of implementing the risky allocation. The net effect of structure and self-selection can lead to an ambiguous relation between trade intensity and structure.

\section{Data, tests, and instruments}

We test our model's predictions using data on all equity mutual funds (crsp_obj_cd starts with 'E') from the CRSP Mutual Fund Database for the period 1993 to 2014. We obtain 
stock prices, returns, and stock-related information from the CRSP stock price database, and monthly return data on the market portfolio, and the SMB, HML, and UMD factors from Kenneth French's online data library. We use the Mutual Fund Links (MFLINKS) database to match funds with stock holdings data from Thompson Financial CDA/Spectrum, and to aggregate multiple classes of the same fund. We add the total net assets under management (TNA) of the different share classes and report the sum as the fund's TNA. We use weighted averages of individual share classes' return, expense, and turnover using their TNAs as weights to represent the corresponding fund attributes. We use the age of the oldest share class as the fund's age. Each quarter, we classify funds that CRSP reports as having two or more managers or reports "team," "management team," or "committee," as "TeamManaged" $(T M)$. We classify all funds with a single manager as "Single-Managed" (SM).

Our final sample consists of 5,651 unique funds. Of these 3,072 funds are still "live" at the end of 2014. Only 851 funds have remained single-managed and 1,795 funds have remained team-managed throughout the sample period. Between 1993 and 2001, the number of singlemanaged funds rose by over $50 \%$ to 1,595 . A precipitous decline since then left only 787 single-managed funds in 2014, more than 25\% fewer than in 1993. In stark contrast, the number of team-managed funds climbed more than eight-fold from 1993 to 2,682 in 2014. Our sample contains 162,449 observations, of which 54,592 are for single-managed funds and 107,857 are for team-managed funds. While these are primarily fund-quarter observations, some observations from the early 1990s are fund-year observations.

Table 1 reports the mean and median values of fund characteristics and the differences in mean (median) characteristics between single-managed and team-managed funds. ${ }^{14}$ All the differences in mean and median values, with the exception of the allocations to bonds (Bonds), are significant. Team-managed funds are larger with average (median) assets of $\$ 877.0$ million (\$150.7 million) compared with $\$ 715.8$ million $(\$ 106.9$ million) for singlemanaged funds. Team-managed funds tend to invest significantly more of their assets in

\footnotetext{
${ }^{14}$ We test median differences using a nonparametric approach and the asymptotic $z$ statistic.
} 
stocks; the average (median) stock holding of team-managed funds is $89.8 \%(94.9 \%)$ versus $88.8 \%$ (94.2\%) for single-managed funds. The average expense ratio for team-managed funds is significantly lower (1.28\% vs $1.39 \%)$. Team-managed funds also have significantly lower asset turnover (Turnover). The average number of years since fund inception (Age) is 9.08 for single-managed funds and slightly higher (9.67) for team-managed funds. These statistics echo evidence in earlier research. For example, Karagiannidis (2010) also finds that teammanaged funds have higher stock holdings and lower turnover. Bär et al. (2010) report that team-managed funds are larger, have lower turnover, and charge lower fees.

\section{A Assessing fund performance}

To test our predictions about the relation between fund management structure and performance, we follow Chen et al. (2004), Bär et al. (2010), and Massa et al. (2010) and regress fund abnormal return, $a r_{i, t}$, on a dummy variable $(T M)$ that takes the value of one if a fund is team managed and zero otherwise. Specifically, we estimate the following model:

$$
a r_{i, t}=\beta_{0}+\beta_{1} \mathrm{TM}+\beta_{p} \text { Controls }+\gamma_{s} \text { Style Dummies }+u \text {. }
$$

To estimate a fund's abnormal return in a given month using returns for the previous 60 months. ${ }^{15}$ To estimate Equation 13 and all the remaining regressions explaining fund performance we use one period (quarter) lagged fund characteristics as controls. We also include the dummy variable Post, which indicates periods after the most recent financial crisis (after June 2009). In the interest of brevity, we focus our attention on tests based on abnormal fund returns derived using the Carhart four-factor model.

We depart from earlier studies such as Chen et al. (2004), Bär et al. (2010), and Massa et al. (2010) by controlling for potential endogeneity bias that our model predicts arises since managers self-select into management structures based on their abilities. We use four distinct approaches to control for the endogeneity bias. Our results are consistent across

\footnotetext{
${ }^{15}$ We estimate monthly abnormal returns, compound them to quarterly (yearly) measures, and then divided by 3 (12) to obtain the average monthly performance measures. We do this to avoid the bias caused by annual observations in our sample. Our results hold qualitatively if we exclude the annual observations.
} 
all approaches. In our first approach, which we refer to as the Linear $I V$ approach, we first estimate the following model of fund management structure using OLS:

$$
\mathrm{TM}=\beta_{0}^{1}+\beta_{1}^{1} \mathrm{IV}+\beta_{p}^{1} \text { Controls }+\gamma_{s}^{1} \text { Style Dummies }+\epsilon,
$$

where $I V$ is an instrumental variable that is both relevant and captures variation in $T M$, and exogenous, i.e., not a function of managerial ability. Equation (14) includes the controls we employ in Equation (13), our fund performance model. We use our estimate of Equation (14) to construct a fitted value for the dummy variable $T M$ to estimate (in the second-stage regression) the fund performance equation (13).

Our second endogeneity-correction approach, which we refer to as the Control Function approach, corrects for endogeneity by introducing a proxy for the omitted variable into the fund performance regression. The endogeneity of the variable TM arises from the correlation of the error term, $\epsilon$ in Equation (14), our model of fund management structure and the error term, $u$ in Equation (13), our fund performance model. Consider the linear projection

$$
u=\rho \epsilon+e .
$$

By definition, $e$ is not correlated with $\epsilon$ in Equation (14). Using Equation (15) to substitute for the error term in Equation (13) gives

$$
a r_{i, t}=\beta_{0}+\beta_{1} \mathrm{TM}+\beta_{p} \text { Controls }+\gamma_{s} \text { Style Dummies }+\rho \epsilon+e,
$$

In Equation (16), by construction, the variable $T M$ is no longer correlated with the error term $e$. Note that, while $\epsilon$ in Equation (16) is not observed, it can be estimated using the residual from our model of fund management structure, Equation (14). While the Control Function approach is likely to yield similar estimates to the Linear IV approach, it has a distinct feature: the test of the significance of the coefficient $\rho$ is a transparent test for the presence of endogeneity in Equation (13), our fund performance model.

While a linear regression model of the dummy variable TM is reasonable, a Probit model is more robust and efficient (Angrist and Krueger, 2001; Wooldridge, 2002). Therefore, we also reformulate our fund management structure model, Equation (14), as an endogenous 
treatment model with a latent decision variable as follows:

$$
\begin{gathered}
\mathrm{MG}=\beta_{0}^{1}+\beta_{1}^{1} \mathrm{IV}+\beta_{p}^{1} \text { Controls }+\gamma_{s}^{1} \text { Style Dummies }+\epsilon, \\
\mathrm{TM}= \begin{cases}1 & \text { if } \mathrm{MG}>0 \\
0 & \text { otherwise }\end{cases}
\end{gathered}
$$

We simultaneously estimate Equations (17) and (13) using maximum likelihood and refer to this approach to estimating the performance and organizational structure relation as the Probit Treatment approach. Our final endogeneity-correction approach, which we refer to as the Heckman approach, uses the inverse Mill's ratio from Equation (17) as an additional control in the fund performance model, Equation (13) (see, e.g. Heckman, 1978; Maddala, 1983; Vella and Verbeek, 1999). The coefficient estimate on the inverse Mills ratio provides insight into the relation between the omitted variable in our model of fund management structure and fund performance.

\section{$B \quad$ Assessing asset allocations}

To examine the relation between fund management structure and fund allocations, we first identify the benchmark allocation for each fund. Each quarter we construct proxies for these benchmark allocations as follows: we first assign each fund to a style, which we identify using a strong style regressions with nine $(3 \times 3)$ size and book-to-market portfolios. To form these nine portfolios, we sort CRSP stocks into three size groups (Small Cap, Midcap, and Large Cap) and three book-to-market groups (Growth, Blend, and Value) using NYSE breakpoints. We estimate each fund's style regression using all monthly returns for the fund within the sample period. We constrain the style regression coefficients to be non-negative and to sum to one (strong style regression). Each fund's style classification is based on the largest coefficient in the fund's style regression. ${ }^{16}$

\footnotetext{
${ }^{16}$ On average, our style regressions account for $78.6 \%$ of the variation in fund returns. Growth funds tend to mimic the benchmark indices more closely than do value funds ( $80.7 \%$ versus $69.5 \%)$. Large cap funds tend to mimic their benchmarks more closely than small cap funds ( $77.8 \%$ versus $75.3 \%)$. Regardless of fund style, team-managed funds tend to have a significantly larger style-regression $R^{2}$ than their single-managed counterparts ( $79.8 \%$ versus $77.2 \%)$. These results support our hypothesis that team-managed funds are less
} 
Each quarter, each style group's benchmark allocation is the average weighting for each stock held by funds in the style group across all funds in that style group. For each quarter, we then estimate the difference between the allocations made by each fund and its style benchmark as follows: we compute the squared difference between the weighting of each stock the fund holds and its style's benchmark weighting for the stock. We normalize this measure by the variance of the style-adjusted stock holdings. Specifically, let $w_{i j t}$ represent the weighting of stock $j$ in fund $i$ at time $t, n_{i t}$ represent the number of distinct stocks in fund $i$ at time $t, K_{t}$ represent the set of funds in fund $i$ 's style group at time $t$, and \# $\left(K_{t}\right)$ represent the number of funds in the style group $K_{t}$. Then our measure of a fund's average scaled weighting deviation from its style index is given by pct $\triangle P O S_{i t}$, where

$$
\begin{gathered}
p c t \triangle P O S_{i t}=\frac{\sum_{j} p c t \Delta P O S_{i j t}}{n_{i t}}, \\
\text { where } \quad p c t \Delta P O S_{i j t}=\frac{\Delta P O S_{i j t}}{\sigma_{j K_{t}}^{2}} \times 100 \%, \\
\Delta P O S_{i j t}=\left(w_{i j t}-\frac{\sum_{k \in K_{t}} w_{k j t}}{\#\left(K_{t}\right)}\right)^{2}, \sigma_{j K_{t}}^{2}=\operatorname{Var}_{i \in K_{t}}\left(w_{i j t}\right) .
\end{gathered}
$$

To examine the relation between fund management structure and deviations from benchmark allocations, we estimate the following regression:

$$
\text { pct } \triangle P O S_{i t}=\beta_{0}+\beta_{1} \mathrm{TM}+\beta_{p} \text { Controls }+\gamma_{s} \text { Style Dummies }+u \text {. }
$$

The coefficient on TM captures the differential effect of fund management structure. To estimate this regression and all the remaining regressions explaining deviations from benchmark allocations we use one period (quarter) lagged fund characteristics and the Post dummy as controls. We use the four techniques we have outlined in the previous section to account for the potential endogeneity bias that our model predicts arises from manager self-selection.

\section{Instrumental variable}

We employ a characteristic of fund family organizational structure as an instrument for TM. Consistent with our modeling assumption, Bär et al. (2010) find that fund families tend 
to impose a uniform management structure their funds. Therefore, we believe that the ratio of the number of team-managed funds in a fund family over the total number of funds in that fund family, \% Team Managed, is a relevant instrument. ${ }^{17}$ On average, $58.1 \%$ funds in a family are team managed (median of 62.1\%). For single-managed funds, the mean of \% Team Managed is $36.2 \%$ (median is $34.4 \%$ ), and for team-managed funds, it is $76.7 \%$ (median is $81.7 \%$ ). Consistent with Bär et al. (2010), the differences between the mean and median values of \% Team Managed for team-managed and single-managed funds are highly significant. This supports our conjecture that \% Team Managed is a relevant instrument. Later, we provide additional evidence that \% Team Managed is a relevant instrument.

We have good reason to believe that \% Team Managed is exogenous since evidence suggests that it is determined by fund families' organizational considerations and not by their desire to attract managers of a particular type. For example, Bär et al. (2010) find that families that manage large and manage complex funds prefer team management, and attribute this preference to the families' need for organizational clarity. Massa et al. (2010) support this argument and suggest that fund marketing may be difficult if a family maintains both single-managed and team-managed funds. The change in Fidelity's marketing strategy to emphasize its stable of team-managed funds is consistent with this argument. Later we demonstrate that our results are robust even if \% Team Managed is not strictly exogenous.

\section{Fund performance}

Proposition 3 predicts that, holding constant manager ability, team-managed funds will generate superior performance, though their superiority may be masked if one does not control for managerial self-selection. We present tests of these predictions in Panel A of Table 2, which contains estimates of both fund management structure models, Equations (14) or (17),

\footnotetext{
${ }^{17}$ We have examined the following instrument candidates suggested by previous studies in unreported tests: Northeast, a dummy variable that takes the value of one if the fund advisor is located in the northeast region close to either Boston or New York and zero otherwise (Massa et al., 2010), and LN(\#FUNDS), the $\log$ of number of funds managed by the fund family (Chen, Hong, Jiang, and Kubik, 2013). We find that Northeast is a weak instrument. While using $L N(\# F U N D S)$ yields estimates that are consistent with the ones we report below, the estimates appear unrealistically large.
} 
and the performance model, Equation (13). The $t$-statistics are adjusted for clustering by fund. ${ }^{18}$

Both the OLS and Probit fund management structure model estimates indicate that \% Team Managed is a highly relevant instrument for TM. The adjusted $R^{2}$ for the OLS estimate and the pseudo $R^{2}$ for the Probit estimate are similar and about $47 \%$. The coefficient estimates for \% Team Managed are highly significant. The relevance test for the instrument, which is the $F$-test of the instrument in the first stage regression, is highly significant with a $p$-value of zero. Moreover, \% Team Managed has a strong economic relation with team management: based on the Probit estimates, increasing the percentage of family funds that are team managed by $1 \%$ results in a $0.76 \%$ increase in the probability of team management.

The OLS estimate of the coefficient for the dummy variable TM is 3.97 and is statistically significant at the one percent level in our fund performance model. The average treatment effect for the OLS estimate is 47.6, which suggests that team-management will add economically significant almost half a percent to a fund's annual abnormal return. All our endogeneity-correction approaches yield uniformly positive, perceptibly higher and highly statistically significant estimates of the effect of team-management on fund performance. Both, the Linear IV and Control Function approaches yield coefficient estimates of 9.64 for TM. ${ }^{19}$ Using the Probit treatment and Heckman approaches, we estimate the coefficient on $T M$ to be 8.96 and 8.44 , respectively. All four average treatment effect estimates suggest that team-management structure raises abnormal performance by over one percent a year.

\footnotetext{
${ }^{18}$ We use Stata command "etregress" for the Probit treatment approach and the Heckman approach, which does not allow for clustering in Heckman approach. In this case, the $t$-statistics are based on bootstrapped estimates. In unreported results, we have estimated both the fund performance and benchmark allocation deviation regressions we present in the next section after clustering by both fund and quarter. We have also estimated these regressions using a Fama-MacBeth type approach with recursive samples which include all observations before each quarter as well as rolling samples which only include previous 60 quarters. Our results are qualitatively unchanged.

${ }^{19}$ One concern with using $\%$ Team Managed to instrument for TM is that both are identical for families with only one fund. While one fund families are common, they account for only $4.4 \%$ of our observations. Families with more than 10 funds account for the vast majority of our observations. To ensure that our results are not an artifact of the closeness between $T M$ and its instrument for small families, we reestimate our regressions for subsamples where we restrict the number of funds in a fund family. Our results are qualitatively unchanged. For example, if we exclude fund families with less than 9 or 11 funds, the coefficient (t-stat) is still $6.78(3.91)$ and $6.57(3.66)$, respectively.
} 
Our prediction that managerial self-selection masks performance differences between single and team-managed funds is supported by the negative and significant coefficient estimates for $\rho$ under the Control Function and Probit treatment approaches, and for the inverse Mill's ratio under the Heckman approach. When we employ the Linear IV approach, the test for endogeneity, which is a $\chi^{2}$ test, is also highly statistically significant with a test statistic of 28.9 and a $p$-value of zero. These estimates and the marked difference between the OLS and endogeneity-corrected estimates of the fund performance-manager structure relation, supports our view that, if it is not correctly accounted for, managerial ability-based selfselection at least partially masks the superiority of team management.

\section{Management structure and fund allocations}

Proposition 4 predicts that, ceteris paribus, team-managed funds are less likely to deviate from their benchmark allocations. However, because high-ability managers will self-select into single-managed funds we may observe that team-managed fund deviate more from the benchmark allocations. Panel B of Table 2 presents tests of these predictions. For completeness it, also presents estimates of the first-stage regressions, Equations (14) and (17), which we have already presented in Panel A of Table 2.

The OLS estimate of the coefficient for TM is -0.06 in our holdings deviation model, Equation (19). This estimate is statistically insignificant at conventional levels, which suggests that team-managed and single-managed funds make similar allocations. In contrast, all the endogeneity-corrected estimates of TM are negative and highly statistically significant. The Linear IV and Control Function coefficient estimates on TM are -0.44 . We obtain a comparable estimate of -0.47 when we use either the Probit treatment or Heckman approach. These estimates indicate that managers who work for team-managed funds are less likely to deviate from their benchmark allocations. Under the Heckman approach, the coefficient estimate for the inverse Mill's Ratio, Lambda is positive (0.43), as is the coefficient estimate for $\rho$ under the Control Function approach (0.06). Both coefficient estimates are statistically 
significant at the one percent level, supporting the inference that managerial self-selection masks allocation differences between single and team-managed funds. Thus, the estimates in Panel B of Table 2 suggest that, consistent with our model's predictions that team-managed funds will more closely follow benchmark portfolio allocations, and self-selection by managers can mask this economically meaningful conservatism of the team-management structure.

\section{Robustness and additional tests}

We now establish the robustness of our estimates and provide results from additional tests on the effects of fund management structure. To establish robustness we assess the effect of loosening our assumption about strict exogeneity of our instrument, and address the possibility that it may proxy for fund family-level influences on fund performance and asset allocations. We also establish robustness by estimating the fund management structureperformance relation using a mutual fund sample from Morningstar as opposed to CRSP. ${ }^{20}$ We conclude the section by providing evidence on the superiority of team management from tests examining changes in fund management structure.

\section{A Instrument exogeneity}

\% Team Managed is clearly a relevant instrument for TM. We have argued that \% Team Managed is also exogenous because it is determined at the fund family level to help rationalize the family's organizational structure. However, \% Team Managed may proxy for some aspect of fund or fund family structure that influences ability-based self-selection by managers and thus may not be strictly exogenous. We now demonstrate that our results are robust even if \% Team Managed is not strictly exogenous.

For \% Team Managed to be strictly exogenous, it must have zero correlation with the error term, $u$, in Equation (13), the fund-performance model. If strict exogeneity is violated, $\hat{\beta}_{1}^{I V}$, the coefficient estimate on the instrumented TM using the Linear IV approach will be

\footnotetext{
${ }^{20}$ We have also established that our results are robust when we account for anonymous team-management.
} 
biased. Ashley (2009) demonstrates how we can obtain the asymptotic sampling distribution of $\hat{\beta}_{1}^{I V}$ as a function of an assumed covariance between the instrument variable (\% Team Managed) and the error term $u$. Using this method we can assess how our estimate of $\hat{\beta}_{1}^{I V}$ changes if $u$ and \% Team Managed are indeed correlated.

Table 3 displays the instrumented Linear IV coefficient estimates for TM in our fund performance model under progressively weaker assumptions about the exogeneity of \% Team Managed. Panel A displays coefficient estimates for the fund-performance team-management relation. $\delta^{I V}$, the estimated bias in the Linear IV estimate of the effect of TM on fund performance rises monotonically from 0.00 when there is zero covariance (correlation) between $u$ and \% Team Managed, to 8.88 when the assumed covariance (correlation) between $u$ and \% Team Managed $\left(\sigma_{Z u}\right)$ rises to $90(1.82 \%)$. After correcting for the bias, the Linear IV estimate continues to be positive and statistically significant at the $1 \%$ level so long as the covariance between $u$ and $\%$ Team Managed is 70 . Thus, we estimate that team management has a significant positive impact on fund performance even when the correlation between $u$ and \% Team Managed is more than 3.75 times higher than the correlation between $u$ and $T M^{21}$ That is, our inferences about the effect of team management on fund performance are robust even if average fund family structure is far more closely correlated with the error term than the actual management structure of the given fund. Moreover, so long as the covariance between $u$ and $\%$ Team Managed is no higher than 50, we estimate that, consistent with manager self-selection masking the benefit of team management, the OLS estimate of fundperformance team-management relation understates the true impact of team management. Hence, even if $u$ and \% Team Managed are fairly highly correlated relative to the correlation

\footnotetext{
${ }^{21}$ Our estimates suggest a relatively low degree of correlation between team management and returns. However, this is expected given that, in an efficient market, returns primarily reflect the arrival of new (and thus unpredictable) information. To provide some perspective on the magnitude of the correlation between $T M$ dummy and returns, we estimate the correlation between $T M$ and simulated returns in the absence of endogeneity. To simulate returns, we first estimate the time-series standard deviation of the abnormal returns estimated using the CAPM. We then simulate the error term using this estimated standard deviation and add back the expected return each month. Finally, we add an alpha of 20 basis points if the fund is a team-managed fund. The equation used to simulate the returns $\left(s r_{t}\right)$ is $s r_{t}=0.002 \times T M+\hat{\beta}_{i, m k t} \times$ $\left(R_{m k t, t}-R_{f t}\right)+\sigma \epsilon_{t}$. We compound the monthly returns to quarterly returns and estimate the correlation between the simulated return and the TM dummy. We estimate a correlation of about $1.9 \%$.
} 
it tries to correct, the Linear IV estimate of the fund-performance team-management relation correctly indicates that the OLS estimate is biased and underestimates the impact on fund performance of a switch of single management to team management.

In Panel $\mathrm{B}, \delta^{I V}$, the estimated bias in the Linear IV estimate of the effect of TM on benchmark allocation deviations rises monotonically from 0.00 when there is zero covariance (correlation) between $u$ and \% Team Managed, to 5.82 when the assumed covariance (correlation) between $u$ and $\%$ Team Managed $\left(\sigma_{Z u}\right)$ rises to $90(23.9 \%)$. The bias-corrected IV coefficient remains negative and statistically significant at the one percent level so long as the covariance (correlation) between $u$ and \% Team Managed is positive. Only when the covariance is negative does the coefficient cease to be significant. Thus, even if $u$ and \% Team Managed are highly correlated, so long as the correlation is positive, the Linear IV estimate of the benchmark allocation-deviation team-management relation correctly indicates that team managed fund will deviate less. Moreover, the OLS estimate of the relation will tend to understate the conservatism of team management.

\section{$B \quad$ Fund family effects}

Since our instrument, \% Team Managed, is based on fund family level data, it may proxy for other family level variables such as shared research from a common research facility that could affect fund performance and asset allocations. For example, the asset allocations of and abnormal returns earned by funds in a family will be correlated if managers follow common research produced for their family's funds. Hence, to establish the robustness of our results, we first introduce fund-family fixed effects in our regressions. We also repeat our analysis after including time-varying controls for commonalities in asset allocations across funds in a family. ${ }^{22}$ The results, which we report in Table 4 , demonstrate that our estimates of the effect of team-management on fund performance and allocation deviations are unlikely to be the result of \% Team Managed proxying for family-level variables such as shared research.

\footnotetext{
${ }^{22}$ We also construct the family correlation measure using fund excess returns and obtain similar results.
} 
First consider Panel A where we report the effect of adding fund family fixed effects. The coefficients estimates on \% Team Managed in the first-stage regressions are close to our baseline estimates in Tables 2. In the second-stage fund performance regressions, the coefficient estimates on TM are uniformly higher than their counterparts in Panel A of Table 2 and above 14 bps for all four approaches. Consistent with these increases, the coefficient estimates on the inverse Mill's ratio in the Heckman estimate and $\rho$ in the Control Function estimate decline, while the average treatment effect estimates rise by more than $50 \%$. When we examine deviations from benchmark allocations, the coefficient estimates on TM while negative are closer to zero than their counterparts in Panel B of Table 2. Moreover, they are no longer statistically significant, which suggests that deviations from benchmark allocations are consistent across funds within a family and relatively stable over time. The coefficient estimates on the inverse Mill's ratio in the Heckman approach and $\rho$ in the Control Function approach decline but remain significant at the five percent level. Thus, our empirical estimates of the effect of team-management on fund performance are robust to our choice of fixed effects. While we no longer find a significant statistical relation between team-management and deviations from benchmark allocations, we continue to find evidence consistent with self-selection by fund managers into fund management structures.

To construct a measure that captures of time varying commonalities across family funds, we first estimate family level holdings deviations by averaging the holdings deviations for each fund estimated in Section $\mathrm{V}$ across all funds in a family. Then, we estimate the correlation between a fund's holdings deviation and its family average deviation using a rolling window of the past 5 years. Finally, we average these correlations across all funds in a family to obtain the family correlation measure. We use this measure to control for fund family-level effects that \% Team Managed might proxy for.

Panel B of Table 4 shows that the family correlation variable has positive coefficients in the first-stage regressions and is statistically significant in the Probit regression. However, the coefficient estimates on \% Team Managed in the first-stage regressions are virtually 
unchanged from Table 2. In the second-stage fund performance regressions, the coefficients on TM are perceptibly smaller than in Panel A of Table 2, but remain highly statistically and economically significant. All four estimates of the average treatment effect exceed 65 bps. In the second-stage holding-deviation regressions, consistent with our predictions, the coefficients on TM are all negative and statistically significant.

\section{Morningstar sample}

All our tests thus far employ data from CRSP. Fund performance and management structure data is also available from Morningstar, which appears to cover different funds than CRSP. The quality of Morningstar's information may also be different. Hence, we now reestimate our fund management structure-fund performance regressions using data from Morningstar, and establish that our results are robust to the choice of data source.

We use Morningstar Direct to extract fund information for all equity funds with an inception date before January 1, 2011 for the period from January 1993 to December $2014 .^{23}$ As we did with the CRSP sample, we aggregate different shares of the same fund into one fund. Using detailed information on fund managers in Morningstar we identify a fund as team-managed if it has two or more managers. ${ }^{24}$ Table 5 reports both first-stage and secondstage regression estimates for the fund management structure-fund performance relation. We construct these estimates using \% Team Managed as our instrument. The first-stage OLS (Probit) coefficient estimate for \% Team Managed is 1.00 (3.74), which is comparable to the OLS (Probit) coefficient estimate of 1.02 (3.75) we obtain using CRSP data. Like the CRSP-based estimates, these estimates are also statistically significant at the one percent

\footnotetext{
${ }^{23}$ We impose this filter to reduce the number of funds to be downloaded from Morningstar because of download limitations imposed by Morningstar Direct.

${ }^{24}$ Our final Morningstar dataset consists of 4,378 unique funds, about $23 \%$ fewer than in our CRSP sample. Of these funds 1,894 have experienced at least one change in management structure, 1,848 have remained team-managed, and 639 have remained single-managed throughout the sample period. The sample contains 114,064 fund-quarter observations, about 30\% fewer than in our CRSP sample. Of these observations 85,042 are for team-managed funds and 29,022 observations are for single-managed funds. Using fund Cusips to match our CRSP and Morningstar samples, we find 2,079 unique funds and 60,400 fund-quarter observations that are common to both samples. CRSP and Morningstar classify 1,029 unique funds, which account for 8,361 fund-quarter observations, differently in terms of their management structures.
} 
level and highly relevant with a $p$-value of zero.

Consistent with our CRSP-based estimates, the OLS and second-stage regressions uniformly indicate that team-managed fund perform better than single-managed funds. The OLS estimate for the coefficient on TM is 1.99 and statistically significant at the ten percent level. The remaining estimates are much larger and more statistically significant. For example, the second-stage Probit Treatment coefficient estimate on TM is 5.74 and the Heckman estimate is even higher at 5.98. The Probit Treatment estimate is significant at the five percent level and the Heckman estimate at the one percent level. Both tests also indicate that the OLS estimates suffer from statistically significant endogeneity bias. The Linear IV and Control Function approaches yield lower return estimates for the effect of team management on fund performance with weaker statistical significance. Overall, while estimates of the effect of team management on fund performance are slightly weaker when we use Morningstar data, the results support our predictions that team management is superior performance but its superiority may be at least partially masked by managerial self-selection.

\section{Switching fund management}

We do not model changes in fund management structure. However, if our model's predictions about the superiority of team-management is indeed correct, funds should display a propensity to switch to team-management, and the switch should improve performance. In contrast, performance should deteriorate when funds switch to single management. We now present evidence that supports these predictions.

A uniform change in fund management structure across many funds in a family is likely to be the result of organizational changes at the family level and is unlikely to be motivated by a influx of high or low ability managers into the fund family. Hence, such changes can be viewed as "exogenous" from the perspective of managerial skill-based self selection. Therefore, we first examine the effect on fund performance of such "wholesale" fund management structure changes. We focus on families where no funds in a family switch their management 
structure and families where at least $50 \%, 70 \%$, or $90 \%$ of funds switch their fund management structures in the same direction-single to team or team to single-and no funds switch their management structures in the opposite direction. ${ }^{25}$ Our model of the relation between the change in fund performance and change in fund management structure is the same as our fund performance model, Equation (13), with the exception that we replace all the variables in Equation (13) with their change relative to the previous quarter. The dummy variable $S W T$, which equals one if a fund switches its management structure and zero otherwise, takes the place of TM. Since the management structure changes are "exogenous", we use OLS to estimate the model. ${ }^{26}$ Panel A of Table 6 reports the results. The estimates indicate that switching to team-management significantly improves fund performance and the improvement is larger if more funds in a family switch at the same time. In contrast, switching to single-management significantly lowers fund performance, and performance deteriorates by more when the switches to single-management are more wide-spread. This evidence clearly supports that hypothesis that team-management structure is superior.

Panel B in Table 6 reports regressions that predict management structure changes conditional on past fund performance and family-level organizational change. We estimate a model that is similar to Equation (14) but the dependent variable is the switch dummy, $S W T$, and in addition to changes in lagged fund characteristics the explanatory variables include the one quarter lagged change in \% Team Managed $\left(\Delta(\% \text { Team Managed })_{t-1}\right)$ and the last two quarters abnormal returns, $\alpha_{\text {Carhart }, t-1}$ and $\alpha_{\text {Carhart }, t-2}$. The estimates indicate that past performance and the change in \% Team Managed in the previous quarter significantly predict switching from single-management to team-management. It appears that switches to team management within a family occur in a staggered manner, and poorly performing

\footnotetext{
${ }^{25}$ The average number of funds in a fund family that switches from single-management to teammanagement is $23.6,21.4$, and 19.4 for cutoffs at $50 \%, 70 \%$, and $90 \%$, respectively, and is $20.0,25.4$, and 28.5 for cutoffs at $50 \%, 70 \%$, and $90 \%$, respectively, for fund families that switch from team-management to single-management.

${ }^{26}$ When we use techniques that correct for endogeneity, the tests for endogeneity are insignificant. Our results are also unchanged if we control for changes in family-level allocation correlations to account for changes in family-level variables such as shared research.
} 
funds are likely to switch to team management. In contrast, the change in \% Team Managed and past performance have no significant predictive power for switches to single-management. These results suggest that switches to single-management are not systematically tied to fund performance or changes in fund family organization.

Panel $\mathrm{C}$ in Table 6 is similar to Panel A except that we include all management structure switches by funds. Such switches may be "endogenous". Hence, we use the change in \% Team Managed $(\Delta(\%$ Team Managed $))$ to instrument the management structure switch indicator, SWT and estimate the relation between the change in fund performance and change in fund management structure by replacing the variables in Equations (13), (14), and (17) with their corresponding differences. The OLS estimate of the coefficient for $S W T$ is positive but statistically insignificant for switches to team management. After instrumenting for SWT, the coefficients becomes large. While the estimates are statistically insignificant when we use the Linear IV or Control Function approaches, they are highly statistically significant when we use the Probit Treatment or Heckman approaches. ${ }^{27}$ The significance of the residual (correlation or lambda) indicates that the OLS estimate of the effect of switching to team management suffers from endogeneity bias. When we examine the effect of switching to single management, the OLS coefficient is positive and statistically significant, but none of the endogeneity-corrected coefficients is statistically significant.

\section{Conclusion}

This paper develops a model to examine difference in the performance, asset allocation, and trading behavior between team-managed and single-managed funds, and empirically investigates these differences. Our model predicts that team-managed funds will generate superior performance, deviate less from their benchmark allocations, and trade less in response to information arrival than single-managed funds. However, these differences may be masked by the rational and endogenous self-selection of high-ability managers into single-

\footnotetext{
${ }^{27}$ If we exclude fund families with relatively few funds switching management structure, the coefficient for instrumented $S W T$ is statistically significant when we use the linear endogeneity-correction approaches.
} 
managed funds. This self-selection is based on a tradeoff of the informational advantages enjoyed as a result of team-membership against the disadvantage of having to share the rewards of success with team members.

Our evidence supports our predictions. If we do not control for managerial self-selection, consistent with the literature, we find some evidence that team-managed funds underperform single-managed funds. However, once we account for endogenous self-selection by managers, team-managed funds outperform single-managed funds. The contrast between unconditional underperformance and selection-conditioned outperformance supports our model's prediction that the best and brightest managers select into individual management. Our evidence on allocation and trading behavior also supports our models predictions that team-managed fund will act more conservatively: they will deviate less from their benchmark indicates and trade less aggressively in response to the arrival of information. In both sets of tests, controlling for managerial self-selection has a noticeable impact on our results. These changes are consistent with our model's prediction that high-ability manager, who will select singlemanaged funds, will be less likely to deviate from their benchmark indices and will trade less aggressively in response to the arrival of information.

\section{References}

Alchian, A. A., and H. Demsetz. "Production, Information Costs, and Economic Organization." American Economic Review, 62 (1972), 777-795.

Angrist, J. D., and A. B. Krueger. "Instrumental Variables and the Search for Identification: From Supply and Demand to Natural Experiments." Journal of Economic Perspectives, 15 (2001), 69-85.

Ashley, R. "Assessing the Credibility of Instrumental Variables Inference with Imperfect Instruments via Sensitivity Analysis." Journal of Applied Econometrics, 24 (2009), 325337.

Bär, M.; A. Kempf; and S. Ruenzi. "Team Management and Mutual Funds." Unpublished 
working paper, University of Cologne. (2005).

Bär, M.; A. Kempf; and S. Ruenzi. "Is a Team Different from the Sum of its Parts? Evidence from Mutual Fund Managers." Review of Financew, 15 (2010), 359-396.

Barry, C. B., and L. T. Starks. "Investment Management and Risk Sharing with Multiple Managers." Journal of Finance, 39 (1984), 477-491.

Berk, J. B., and R. C. Green. "Mutual Fund Flows and Performance in Rational Markets." Journal of Political Economy, 112 (2004), 1269-1295.

Blinder, A. S., and J. Morgan. "Are Two Heads Better Than One?: An Experimental Analysis of Group vs. Individual Decisionmaking." Unpublished working paper (2001).

Bliss, R. T.; M. E. Potter; and C. Schwarz. "Performance characteristics of individuallymanaged versus team-managed mutual funds." Journal of Portfolio Management, 34 (2008), $110-119$.

Bone, J.; J. Hey; and J. Suckling. "Are Groups More Consistent than Individuals?" Journal of Risk and Uncertainty, 18 (1999), 63-81.

Carhart, M. M. "On Persistence in Mutual Fund Performance." Journal of Finance, 52 (1997), 57-82.

Chen, J.; H. Hong; M. Huang; and J. D. Kubik. "Does Fund Size Erode Mutual Fund Performance? The Role of Liquidity and Organization." American Economic Review, 94 (2004), 1276-1302.

Chen, J.; H. Hong; W. Jiang; and J. D. Kubik. "Outsourcing mutual fund management: Firm boundaries, incentives, and performance." Journal of Finance, 68 (2013), 523-558.

Gervais, S.; A. W. Lynch; and D. K. Musto. "Fund families as delegated monitors of money managers." Review of Financial Studies, 18 (2005), 1139-1169.

Gomes, A., and W. Novaes. "Sharing of control versus monitoring as corporate governance mechanisms." Unpublished working paper, Washington University (2006).

Heckman, J. J. "Dummy Endogenous Variables in a Simultaneous Equation System." Econometrica, 46 (1978), 931-959. 
Hill, G. W. "Group Versus Individual Performance: Are N + 1 Heads Better Than One?" Psychological Bulletin, 91 (1982), 517-539.

Huang, J.; C. Sialm; and H. Zhang. "Risk Shifting and Mutual Fund Performance." Review of Financial Studies, 24 (2011), 2575-2616.

Kacperczyk, M., and A. Seru. "Fund Manager Use of Public Information: New Evidence on Managerial Skills." Journal of Finance, 62 (2007), 485-528.

Kacperczyk, M.; C. Sialm; and L. Zheng. "On the industry concentration of actively managed equity mutual funds." Journal of Finance, 60 (2005), 1983-2011.

Karagiannidis, I. "Management team structure and mutual fund performance." Journal of International Financial Markets, Institutions and Money, 20 (2010), 197-211.

Maddala, G. S. Limited-dependent and Qualitative Variables in Econometrics. Cambridge University Press, Cambridge (1983).

Massa, M.; J. Reuter; and E. W. Zitzewitz. "When should firms share credit with employees? Evidence from anonymously managed mutual funds." Journal of Financial Economics, 95 (2010), 400-424.

Pelled, L. H.; K. M. Eisenhardt; and K. R. Xin. "Exploring the Black Box: An Analysis of Work Group Diversity, Conflict, and Performance." Administrative Science Quarterly, 44 (1999), 1 .

Reuters. "Fidelity says to offer team-managed funds." (2007).

Sharpe, W. F. "Decentralized Investment Management." Journal of Finance, 36 (1981), $217-234$.

Vella, F., and M. Verbeek. "Two-step estimation of panel data models with censored endogenous variables and selection bias." Journal of Econometrics, 90 (1999), 239-263.

Wooldridge, J. M. Econometricic Analysis of Cross Section and Panel Data. The MIT Press, Cambridge, Massachusetts (2002). 


\section{Table 1}

\section{Fund Characteristics Comparison}

This table reports summary statistics of fund characteristics for all funds (All), singlemanager funds (Single), and team-managed funds (Team) during the sample period from January 1993 to December 2014. For each fund, we calculate the time-series average for each fund characteristic. The statistics presented are for the resulting cross-sectional distributions of these time-series averages of fund characteristics. We report the differences between the mean (median) fund characteristics of single-manager and team-managed funds (Differ), along with their $t$-stats ( $z$-stats). The fund characteristics are the fund assets in millions of dollars (TNA), the percentage of assets that a fund holds in cash, stocks, and bonds (Cash, Stocks, and Bonds, respectively), turnover (Turnover), expense ratio (Expenses) as a percentage of total assets under management, and the years since fund inception (Age). Significance at the $1 \%$ and $5 \%$ levels is denoted by superscript a and b, respectively.

\begin{tabular}{lccccccccc}
\hline \hline \multirow{2}{*}{ Variable } & \multicolumn{5}{c}{ Mean } & \multirow{2}{*}{ Differ } & \multicolumn{5}{c}{ Median } & \multirow{2}{*}{ Differ } \\
\cline { 2 - 3 } \cline { 7 - 8 } & All & Single & Team & & All & Single & Team nn & \\
\hline TNA & $802.7^{\mathbf{a}}$ & $715.8^{\mathbf{a}}$ & $877.0^{\mathbf{a}}$ & $-161.3^{\mathbf{b}}$ & 129.6 & 106.9 & 150.7 & $-43.8^{\mathbf{a}}$ \\
& $(23.5)$ & $(14.6)$ & $(18.4)$ & $(-2.36)$ & & & & $(-5.80)$ \\
Cash & $4.61^{\mathbf{a}}$ & $5.11^{\mathbf{a}}$ & $4.20^{\mathbf{a}}$ & $0.91^{\mathbf{a}}$ & 2.66 & 3.11 & 2.32 & $0.79^{\mathbf{a}}$ \\
& $(41.4)$ & $(38.1)$ & $(24.5)$ & $(4.18)$ & & & & $(11.3)$ \\
Stocks & $89.3^{\mathbf{a}}$ & $88.8^{\mathbf{a}}$ & $89.8^{\mathbf{a}}$ & $-1.02^{\mathbf{b}}$ & 94.6 & 94.2 & 94.9 & $-0.70^{\mathbf{a}}$ \\
& $(414.8)$ & $(334.2)$ & $(274.3)$ & $(-2.42)$ & & & & $(-5.70)$ \\
Bonds & $0.72^{\mathbf{a}}$ & $0.67^{\mathbf{a}}$ & $0.75^{\mathbf{a}}$ & -0.08 & 0.00 & 0.00 & 0.00 & 0.00 \\
& $(15.6)$ & $(10.7)$ & $(11.5)$ & $(-0.89)$ & & & & $(-12.8)$ \\
Turnover & $1.03^{\mathbf{a}}$ & $1.07^{\mathbf{a}}$ & $0.98^{\mathbf{a}}$ & $0.09^{\mathbf{a}}$ & 0.68 & 0.69 & 0.67 & 0.02 \\
& $(58.5)$ & $(42.3)$ & $(40.7)$ & $(2.58)$ & & & & $(1.67)$ \\
Expenses & $1.33^{\mathbf{a}}$ & $1.39^{\mathbf{a}}$ & $1.28^{\mathbf{a}}$ & $0.11^{\mathbf{a}}$ & 1.28 & 1.31 & 1.25 & $0.06^{\mathbf{a}}$ \\
& $(149.8)$ & $(85.0)$ & $(146.9)$ & $(5.72)$ & & & & $(4.31)$ \\
Age & $9.40^{\mathbf{a}}$ & $9.08^{\mathbf{a}}$ & $9.67^{\mathbf{a}}$ & $-0.59^{\mathbf{a}}$ & 6.62 & 6.08 & 7.08 & $-1.00^{\mathbf{a}}$ \\
& $(94.1)$ & $(60.2)$ & $(72.7)$ & $(-2.92)$ & & & & $(-7.64)$ \\
\hline \hline
\end{tabular}




\section{Table 2}

\section{Fund Performance, Deviations from Benchmark Allocations and Team Management}

This table presents estimates of the fund-performance management-structure relation in Panel A and the fund-allocation-deviation management-structure relation in Panel B after correcting for self-selection bias. We use monthly abnormal return in basis points (alpha plus residuals) from the Carhart four-factor model to measure fund performance. The fund allocation deviations are measured as the variance-normalized squared deviations (pct $\triangle P O S$ ) from style benchmark portfolios. We employ \% Team Managed, the percentage of team managed funds in a fund family to instrument for the team management dummy $(T M)$ that takes the value of one when the fund is team managed, otherwise zero. $I V T M$ is the instrumented value for the team management dummy, estimated as the fitted value from the $1^{\text {st }}$ stage regression, either a linear regression or Probit model. Resid is the residual used in the $2^{\text {nd }}$ stage regression model (Control Func), Rho is the correlation coefficient estimated from the Probit treatment model, and Lambda is the inverse Mill's ratio used in the Heckman model. For all regressions, we report the average treatment effect (ATES), which is the annualized coefficients on $T M$ in performance regressions and the coefficients themselves in allocation deviation regressions. The control variables are the ones reported in Table 1 plus a dummy indicating the period after the most recent financial crisis (after June, 2009), and a dummy indicating whether the fund is still operating. Each regression also employs fund style dummies to control for style fixed-effects and corrects for fund clustering effects (Heckman uses bootstrap). The total number of observations used (fund and quarter) is 162,449. Significance at the $1 \%$ and $5 \%$ levels is denoted by superscript a and b, respectively. The sample period is from January 1993 to December 2014.

\begin{tabular}{|c|c|c|c|c|c|c|c|}
\hline & \multicolumn{3}{|c|}{ Panel 1: Linear IV } & \multicolumn{3}{|c|}{ Panel 2: Probit Treatment } & \multirow{3}{*}{$\begin{array}{c}\text { Panel 3: OLS } \\
\text { OLS }\end{array}$} \\
\hline & \multirow{2}{*}{$\frac{1^{\text {st }} \text { Stage }}{\text { Linear }}$} & \multicolumn{2}{|c|}{$2^{\text {nd }}$ Stage } & \multirow{2}{*}{$\frac{1^{\text {st }} \text { Stage }}{\text { Probit }}$} & \multicolumn{2}{|c|}{$2^{\text {nd }}$ Stage } & \\
\hline & & IV & Control Func & & Probit Treat & Heckman & \\
\hline & \multicolumn{7}{|c|}{ Panel A: Carhart Four-Factor Abnormal Returns } \\
\hline TM (IV TM) & & $\begin{array}{l}9.64^{\mathrm{a}} \\
(6.27)\end{array}$ & $\begin{array}{l}9.64^{\mathbf{a}} \\
(6.28)\end{array}$ & & $\begin{array}{l}8.96^{\mathbf{a}} \\
(5.70)\end{array}$ & $\begin{array}{l}8.44^{\mathrm{a}} \\
(7.21)\end{array}$ & $\begin{array}{l}3.97^{\mathrm{a}} \\
(4.05)\end{array}$ \\
\hline Resid (Rho, Lambda) & & & $\begin{array}{l}-10.4^{\mathbf{a}} \\
(-5.37)\end{array}$ & & $\begin{array}{l}-0.03^{\mathbf{a}} \\
(-4.54)\end{array}$ & $\begin{array}{l}-4.70^{\mathbf{a}} \\
(-5.17)\end{array}$ & \\
\hline$\%$ Team Managed & $\begin{array}{c}1.02^{\mathbf{a}} \\
(130.13)\end{array}$ & & & $\begin{array}{c}3.75^{\mathbf{a}} \\
(73.34)\end{array}$ & & & \\
\hline \multirow[b]{3}{*}{ TM (IV TM) } & & $\begin{array}{l}115.7^{\mathbf{a}} \\
(6.27)\end{array}$ & $\begin{array}{l}115.7^{\mathrm{a}} \\
(6.28)\end{array}$ & & $\begin{array}{l}107.5^{\mathbf{a}} \\
(5.70)\end{array}$ & $\begin{array}{l}101.3^{\mathbf{a}} \\
(7.21)\end{array}$ & $\begin{array}{l}47.6^{\mathbf{a}} \\
(4.05)\end{array}$ \\
\hline & \multicolumn{7}{|c|}{ Panel B: Variance-Normalized Squared Deviations } \\
\hline & & $\begin{array}{l}-0.44^{\mathbf{a}} \\
(-2.72)\end{array}$ & $\begin{array}{l}-0.44^{\mathrm{a}} \\
(-2.73)\end{array}$ & & $\begin{array}{l}-0.47^{\mathbf{a}} \\
(-8.39)\end{array}$ & $\begin{array}{l}-0.47^{\mathbf{a}} \\
(-8.28)\end{array}$ & $\begin{array}{l}-0.06 \\
(-0.75)\end{array}$ \\
\hline Resid (Rho, Lambda) & & & $\begin{array}{l}0.69^{\mathbf{a}} \\
(2.79)\end{array}$ & & $\begin{array}{l}0.06^{\mathbf{a}} \\
(5.72)\end{array}$ & $\begin{array}{l}0.43^{\mathbf{a}} \\
(8.68)\end{array}$ & \\
\hline$\%$ Team Managed & $\begin{array}{c}1.02^{\mathbf{a}} \\
(130.13)\end{array}$ & & & $\begin{array}{c}3.75^{\mathbf{a}} \\
(73.34)\end{array}$ & & & \\
\hline ATE & & $\begin{array}{l}-0.44^{\mathbf{a}} \\
(-2.72)\end{array}$ & $\begin{array}{l}-0.44^{\mathbf{a}} \\
(-2.73)\end{array}$ & & $\begin{array}{l}-0.47^{\mathbf{a}} \\
(-8.39)\end{array}$ & $\begin{array}{l}-0.47^{\mathrm{a}} \\
(-8.28)\end{array}$ & $\begin{array}{l}-0.06 \\
(-0.75)\end{array}$ \\
\hline Controls & Yes & Yes & Yes & Yes & Yes & Yes & Yes \\
\hline Style Dummy & Yes & Yes & Yes & Yes & Yes & Yes & Yes \\
\hline Cluster by Fund & Yes & Yes & Yes & Yes & Yes & Bootstrap & Yes \\
\hline
\end{tabular}


Table 3

\section{Exogeneity of IV - Correlation Sensitivity Analysis}

This table examines the robustness of the results to the exclusion assumption of the instrument variable, \% Team Managed, following Ashley (2009). $Z$ denotes the instrument variable, $X$ denotes the endogenous dummy variable $(T M)$, and $u$ denotes the error term of the second stage regression. We vary the covariance between the instrument and the error term $\left(\sigma_{Z u}\right)$, and examine the corresponding changes of other relevant quantities. $\beta_{1}$ is the true coefficient on the team dummy $(T M)$, $\delta^{I V}$ is the bias of the coefficient on the instrumented value of $T M$ relative to the true coefficient $\left(\delta^{I V}=\beta_{1}^{I V}-\beta_{1}\right)$. Similarly, $\delta^{O L S}=\beta_{1}^{O L S}-\beta_{1} \cdot \rho_{X u}\left(\rho_{Z u}\right)$ is the correlation between TM (the instrument) and the error term, abs $\left(\frac{\rho_{Z u}}{\rho_{X u}}\right)$ is the absolute value of the ratio of the two correlation coefficients, and $p$-value is the p-value of the hypothesis that the instrumented coefficient $\beta_{1}^{I V}$ is significant. Panel A is for the performance regression and Panel B is for the deviation regression.

\begin{tabular}{|c|c|c|c|c|c|c|c|}
\hline$\sigma_{Z u}$ & $a b s\left(\frac{\rho_{Z u}}{\rho_{X u}}\right)(\%)$ & $\rho_{Z u}(\%)$ & $\rho_{X u}(\%)$ & $\beta_{1}$ & $\delta^{I V}$ & $\delta^{O L S}$ & $p$-value \\
\hline \multicolumn{8}{|c|}{ Panel A: Fund performance } \\
\hline 0 & 0.00 & 0.00 & -1.71 & 9.64 & 0.00 & -5.67 & 0.00 \\
\hline 10 & 14.3 & 0.20 & -1.41 & 8.66 & 0.99 & -4.68 & 0.00 \\
\hline 20 & 36.3 & 0.40 & -1.11 & 7.67 & 1.97 & -3.70 & 0.00 \\
\hline 30 & 74.2 & 0.60 & -0.82 & 6.68 & 2.96 & -2.71 & 0.00 \\
\hline 40 & 155.6 & 0.81 & -0.52 & 5.70 & 3.95 & -1.72 & 0.00 \\
\hline 50 & 454.7 & 1.01 & -0.22 & 4.71 & 4.93 & -0.74 & 0.00 \\
\hline 60 & $1,615.5$ & 1.21 & 0.07 & 3.72 & 5.92 & 0.25 & 0.00 \\
\hline 70 & 379.9 & 1.41 & 0.37 & 2.74 & 6.91 & 1.24 & 0.01 \\
\hline 80 & 241.4 & 1.61 & 0.67 & 1.75 & 7.89 & 2.22 & 0.07 \\
\hline 90 & 188.1 & 1.82 & 0.97 & 0.76 & 8.88 & 3.21 & 0.26 \\
\hline \multicolumn{8}{|c|}{ Panel B: Benchmark Allocation-Deviation } \\
\hline-4 & $2,330.8$ & -1.71 & -0.07 & -0.05 & -0.39 & -0.01 & 0.20 \\
\hline-3 & 231.7 & -1.29 & 0.56 & -0.15 & -0.29 & 0.09 & 0.01 \\
\hline-2 & 72.4 & -0.86 & 1.18 & -0.25 & -0.19 & 0.18 & 0.00 \\
\hline 0 & 0.00 & 0.00 & 2.44 & -0.44 & 0.00 & 0.38 & 0.00 \\
\hline 10 & 49.1 & 4.27 & 8.69 & -1.41 & 0.97 & 1.35 & 0.00 \\
\hline 20 & 57.1 & 8.48 & 14.8 & -2.38 & 1.94 & 2.32 & 0.00 \\
\hline 30 & 60.4 & 12.6 & 20.8 & -3.35 & 2.91 & 3.29 & 0.00 \\
\hline 40 & 62.2 & 16.5 & 26.6 & -4.32 & 3.88 & 4.26 & 0.00 \\
\hline 50 & 63.3 & 20.3 & 32.1 & -5.29 & 4.85 & 5.23 & 0.00 \\
\hline 60 & 64.1 & 23.9 & 37.3 & -6.26 & 5.82 & 6.20 & 0.00 \\
\hline
\end{tabular}




\section{Table 4}

\section{Controlling for Fund Family Effects}

This table reports results controlling for fund family effects. Estimates in Panel A account for fund family fixed effects in addition to style fixed effect, while Panel B reports results controlling for correlations between benchmark allocation deviations within a fund family. Panels A1 (B1) and A2 (B2) report results using the linear and Probit $1^{\text {st }}$ stage regressions, respectively. The instrument variable is \% Team Managed, the percentage of team managed funds in a fund family. IV TM is the instrumented value for the team management dummy, estimated as the fitted value from the $1^{\text {st }}$ stage regression, either a linear regression or Probit model. Resid is the residual used in the $2^{\text {nd }}$ stage regression model (Control Func), Rho is the correlation coefficient estimated from the Probit treatment model, and Lambda is the inverse Mill's ratio used in the Heckman model. For all regressions, we report the average treatment effect (ATEs), which is the annualized coefficients on TM in performance regressions and the coefficients themselves in allocation deviation regressions. The control variables are the ones reported in Table 1 plus a dummy indicating the period after the most recent financial crisis (after June, 2009), and a dummy indicating whether the fund is still operating. The total number of observations used (fund and quarter) is 162,449. Significance at the $1 \%$ and $5 \%$ levels is denoted by superscript a and b, respectively. The sample period is from January 1993 to December 2014.

\begin{tabular}{|c|c|c|c|c|c|c|c|c|c|c|}
\hline & \multicolumn{10}{|c|}{ Panel A: Fund Family Fixed Effect } \\
\hline & \multicolumn{5}{|c|}{ Panel A1: Linear IV } & \multicolumn{5}{|c|}{ Panel A2: Probit Treatment } \\
\hline & \multirow{2}{*}{$\frac{1^{\text {st }} \text { Stage }}{\text { Linear }}$} & \multicolumn{2}{|c|}{ Performance } & \multicolumn{2}{|c|}{ Deviation } & \multirow{2}{*}{$\frac{1^{\text {st }} \text { Stage }}{\text { Probit }}$} & \multicolumn{2}{|c|}{ Performance } & \multicolumn{2}{|c|}{ Deviation } \\
\hline & & IV & Control Func & IV & Control Func & & Probit Treat & Heckman & Probit Treat & Heckman \\
\hline TM (IV TM) & & $\begin{array}{l}15.6^{\mathbf{a}} \\
(4.68)\end{array}$ & $\begin{array}{l}15.6^{\mathbf{a}} \\
(6.95)\end{array}$ & $\begin{array}{c}-0.16 \\
(-0.85)\end{array}$ & $\begin{array}{c}-0.16 \\
(-1.16)\end{array}$ & & $\begin{array}{l}14.9^{\mathbf{a}} \\
(6.97)\end{array}$ & $\begin{array}{l}14.1^{\mathrm{a}} \\
(6.66)\end{array}$ & $\begin{array}{c}-0.18 \\
(-1.31)\end{array}$ & $\begin{array}{c}-0.20 \\
(-1.48)\end{array}$ \\
\hline Resid (Lambda) & & & $\begin{array}{l}-15.6^{\mathbf{a}} \\
(-6.20)\end{array}$ & & $\begin{array}{l}0.43^{\mathbf{b}} \\
(2.21)\end{array}$ & & & $\begin{array}{l}-7.85^{\mathrm{a}} \\
(-5.79)\end{array}$ & & $\begin{array}{l}0.29^{\mathbf{b}} \\
(2.33)\end{array}$ \\
\hline$\%$ Team Managed & $\begin{array}{c}1.00^{\mathbf{a}} \\
(102.40)\end{array}$ & & & & & $\begin{array}{c}3.89^{\mathrm{a}} \\
(67.97)\end{array}$ & & & & \\
\hline ATE & & $\begin{array}{l}187.2^{\mathrm{a}} \\
(4.68)\end{array}$ & $\begin{array}{l}187.2^{\mathrm{a}} \\
(6.95)\end{array}$ & $\begin{array}{c}-0.16 \\
(-0.85)\end{array}$ & $\begin{array}{l}-0.16 \\
(-1.16)\end{array}$ & & $\begin{array}{l}178.8^{\mathbf{a}} \\
(6.97)\end{array}$ & $\begin{array}{l}169.2^{\mathrm{a}} \\
(6.66)\end{array}$ & $\begin{array}{l}-0.18 \\
(-1.31)\end{array}$ & $\begin{array}{c}-0.20 \\
(-1.48)\end{array}$ \\
\hline Controls & Yes & Yes & Yes & Yes & Yes & Yes & Yes & Yes & Yes & Yes \\
\hline Family+Style Dummy & Yes & Yes & Yes & Yes & Yes & Yes & Yes & Yes & Yes & Yes \\
\hline Cluster by Fund & Yes & Yes & Yes & Yes & Yes & Yes & Yes & Bootstrap & Yes & Bootstrap \\
\hline
\end{tabular}




\begin{tabular}{|c|c|c|c|c|c|c|c|c|c|c|}
\hline & \multicolumn{10}{|c|}{ Panel B: Family Correlation } \\
\hline & \multicolumn{5}{|c|}{ Panel B1: Linear IV } & \multicolumn{5}{|c|}{ Panel B2: Probit Treatment } \\
\hline & \multirow{2}{*}{$\frac{1^{\text {st }} \text { Stage }}{\text { Linear }}$} & \multicolumn{2}{|c|}{ Performance } & \multicolumn{2}{|c|}{ Deviation } & \multirow{2}{*}{$\frac{1^{\text {st }} \text { Stage }}{\text { Probit }}$} & \multicolumn{2}{|c|}{ Performance } & \multicolumn{2}{|c|}{ Deviation } \\
\hline & & IV & Control Func & IV & Control Func & & Probit Treat & Heckman & Probit Treat & Heckman \\
\hline TM (IV TM) & & $\begin{array}{l}7.06^{\mathbf{a}} \\
(4.48)\end{array}$ & $\begin{array}{l}7.06^{\mathbf{a}} \\
(4.48)\end{array}$ & $\begin{array}{l}-0.47^{\mathbf{a}} \\
(-2.68)\end{array}$ & $\begin{array}{l}-0.47^{\mathbf{a}} \\
(-2.68)\end{array}$ & & $\begin{array}{l}5.65^{\mathbf{a}} \\
(4.32)\end{array}$ & $\begin{array}{l}5.65^{\mathbf{a}} \\
(3.61)\end{array}$ & $\begin{array}{l}-0.51^{\mathbf{a}} \\
(-8.41)\end{array}$ & $\begin{array}{c}-0.51^{\mathbf{a}} \\
(-10.70)\end{array}$ \\
\hline Resid (Lambda) & & & $\begin{array}{l}-7.53^{\mathbf{a}} \\
(-3.85)\end{array}$ & & $\begin{array}{l}0.73^{\mathbf{a}} \\
(2.78)\end{array}$ & & $\begin{array}{l}-0.02^{\mathrm{a}} \\
(-3.08)\end{array}$ & $\begin{array}{l}-2.91^{\mathbf{b}} \\
(-2.54)\end{array}$ & $\begin{array}{l}0.06^{\mathbf{a}} \\
(5.71)\end{array}$ & $\begin{array}{c}0.47^{\mathbf{a}} \\
(10.70)\end{array}$ \\
\hline$\%$ Team Managed & $\begin{array}{c}1.02^{\mathbf{a}} \\
(121.24)\end{array}$ & & & & & $\begin{array}{c}3.74^{\mathbf{a}} \\
(251.15)\end{array}$ & & & & \\
\hline Family Correlation & $\begin{array}{c}1.21 \\
(1.43)\end{array}$ & $\begin{array}{l}-11.7^{\mathbf{a}} \\
(-6.92)\end{array}$ & $\begin{array}{l}-11.7^{\mathbf{a}} \\
(-6.92)\end{array}$ & $\begin{array}{l}-0.55^{\mathbf{a}} \\
(-3.23)\end{array}$ & $\begin{array}{l}-0.55^{\mathbf{a}} \\
(-3.24)\end{array}$ & $\begin{array}{c}18.2^{\mathbf{a}} \\
(12.30)\end{array}$ & $\begin{array}{l}-11.7^{\mathbf{a}} \\
(-8.90)\end{array}$ & $\begin{array}{l}-11.7^{\mathbf{a}} \\
(-9.76)\end{array}$ & $\begin{array}{l}-0.55^{\mathbf{a}} \\
(-5.44)\end{array}$ & $\begin{array}{l}-0.55^{\mathbf{a}} \\
(-5.43)\end{array}$ \\
\hline ATE & & $\begin{array}{l}84.7^{\mathbf{a}} \\
(4.48)\end{array}$ & $\begin{array}{l}84.7^{\mathbf{a}} \\
(4.48)\end{array}$ & $\begin{array}{l}-0.47^{\mathrm{a}} \\
(-2.68)\end{array}$ & $\begin{array}{l}-0.47^{\mathbf{a}} \\
(-2.68)\end{array}$ & & $\begin{array}{l}67.8^{\mathbf{a}} \\
(4.32)\end{array}$ & $\begin{array}{l}67.8^{\mathbf{a}} \\
(3.61)\end{array}$ & $\begin{array}{l}-0.51^{\mathbf{a}} \\
(-8.41)\end{array}$ & $\begin{array}{c}-0.51^{\mathrm{a}} \\
(-10.70)\end{array}$ \\
\hline Controls & Yes & Yes & Yes & Yes & Yes & Yes & Yes & Yes & Yes & Yes \\
\hline Style Dummy & Yes & Yes & Yes & Yes & Yes & Yes & Yes & Yes & Yes & Yes \\
\hline Cluster by Fund & Yes & Yes & Yes & Yes & Yes & Yes & Yes & Bootstrap & Yes & Bootstrap \\
\hline
\end{tabular}


Table 5

Fund Performance Comparison Using Morningstar Data

This table contains estimates of the fund-performance management-structure relation using Morningstar data. We use monthly abnormal return in basis points (alpha plus residuals) from the Carhart four-factor model to measure fund performance. We employ is \% Team Managed, the percentage of team managed funds in a fund family to instrument for the team management dummy $(T M)$ that takes the value of one when the fund is team managed, otherwise zero. IV TM is the instrumented value for the team management dummy, estimated as the fitted value from the $1^{s t}$ stage regression, either a linear regression or Probit model. Resid is the residual used in the $2^{\text {nd }}$ stage regression model (Control Func), Rho is the correlation coefficient estimated from the Probit treatment model, and Lambda is the inverse Mill's ratio used in the Heckman model. For all regressions, we report the average treatment effect (ATEs), which is the annualized coefficients on TM in performance regressions and the coefficients themselves in allocation deviation regressions. The control variables are the ones reported in Table 1 plus a dummy indicating the period after the most recent financial crisis (after June, 2009), and a dummy indicating whether the fund is still operating. For all regressions, we report the average treatment effects (ATEs), which are the annualized coefficients on TM. Each regression also employs fund style dummies to control for style fixed-effects and corrects for fund clustering effects (Heckman uses bootstrap). The total number of observations used (fund and quarter) is 113,832. Significance at the $1 \%$ and $5 \%$ levels is given by superscript a and b, respectively. The sample period is from January 1993 to December 2014.

\begin{tabular}{|c|c|c|c|c|c|c|c|}
\hline & \multicolumn{7}{|c|}{ Carhart Four-Factor Abnormal Returns } \\
\hline & \multicolumn{3}{|c|}{ Panel A: Linear IV } & \multicolumn{3}{|c|}{ Panel B: Probit Treatment } & \multirow{3}{*}{$\begin{array}{c}\text { Panel C: OLS } \\
\text { OLS }\end{array}$} \\
\hline & \multirow{2}{*}{$\frac{1^{\text {st }} \text { Stage }}{\text { Linear }}$} & \multicolumn{2}{|c|}{$2^{n d}$ Stage } & \multirow{2}{*}{$\frac{1^{\text {st } \text { Stage }}}{\text { Probit }}$} & \multicolumn{2}{|c|}{$2^{n d}$ Stage } & \\
\hline & & IV & Control Func & & Probit Treat & Heckman & \\
\hline TM (IV TM) & & $\begin{array}{c}4.51 \\
(1.76)\end{array}$ & $\begin{array}{c}4.50 \\
(1.76)\end{array}$ & & $\begin{array}{l}5.74^{\mathbf{b}} \\
(2.36)\end{array}$ & $\begin{array}{l}5.98^{\mathbf{a}} \\
(2.85)\end{array}$ & $\begin{array}{c}1.99 \\
(1.68)\end{array}$ \\
\hline Resid (Rho, Lambda) & & & $\begin{array}{l}-3.46 \\
(-1.19)\end{array}$ & & $\begin{array}{l}-0.02 \\
(-1.91)\end{array}$ & $\begin{array}{l}-3.16^{\mathbf{b}} \\
(-2.02)\end{array}$ & \\
\hline$\%$ Team Managed & $\begin{array}{c}1.00^{\mathrm{a}} \\
(84.24)\end{array}$ & & & $\begin{array}{c}3.74^{\mathbf{a}} \\
(47.83)\end{array}$ & & & \\
\hline ATE & & $\begin{array}{c}54.1 \\
(1.76)\end{array}$ & $\begin{array}{c}54.0 \\
(1.76)\end{array}$ & & $\begin{array}{l}68.9^{\mathbf{b}} \\
(2.36)\end{array}$ & $\begin{array}{l}71.8^{\mathbf{a}} \\
(2.85)\end{array}$ & $\begin{array}{c}23.9 \\
(1.68)\end{array}$ \\
\hline Controls & Yes & Yes & Yes & Yes & Yes & Yes & Yes \\
\hline Style Dummy & Yes & Yes & Yes & Yes & Yes & Yes & Yes \\
\hline Cluster by Fund & Yes & Yes & Yes & Yes & Yes & Bootstrap & Yes \\
\hline
\end{tabular}




\section{Table 6}

\section{Fund Management Switch}

This table reports results about fund management switch. Panel A reports the impact of switch on performance when the switch is "exogenous". Panel B reports the predictive power of the past abnormal returns on switch. Panel C reports the impact of switch on performance when the switch is "endogenous". In Panel A, "exogeneity" is defined as to have at least $50 \%, 70 \%$, or $90 \%$, respectively, of funds in a fund family switching to the same type of management structure and no funds switching to the other direction. The dummy variable $S W T$ takes the value of one when a fund is switched from one type to the other type of managment, and zero otherwise. In Panel B, all variables are lagged by at least one quarter in the predictive regressions. $\Delta(\% \text { Team Managed })_{t-1}$ is the change of $\%$ Team Managed in the previous quarter. $\alpha_{C a r h a r t, t-1}$ and $\alpha_{C a r h a r t, t-2}$ are past abnormal returns. In Panel C, "endogeity" is corrected using changes of \% Team Managed either in a linear model or a Probit model as described previously. IV SWT is the instrumented variable for the switch dummy, estimated as the fitted value from the $1^{\text {st }}$ stage regression, either the linear regression model or the Probit model. Resid is the residual used in the $2^{\text {nd }}$ stage regression model (Control Func), Rho is the correlation coefficient estimated from the Probit treatment model, and Lambda is the inverse Mill's ratio used in the Heckman model. For all regressions, we report the average treatment effect (ATEs), which is the annualized coefficients on TM in performance regressions and the coefficients themselves in allocation deviation regressions. The control variables are the ones reported in Table 1 plus a dummy indicating the period after the most recent financial crisis (after June, 2009), and a dummy indicating whether the fund is still operating. Each regression also employs fund style dummies to control for style fixed-effects and corrects for fund clustering effects (Heckman uses bootstrap). The control variables are used but not reported for brevity. Significance at the $1 \%$ and $5 \%$ levels is denoted by superscript a and b, respectively. The sample period is from January 1993 to December 2014.

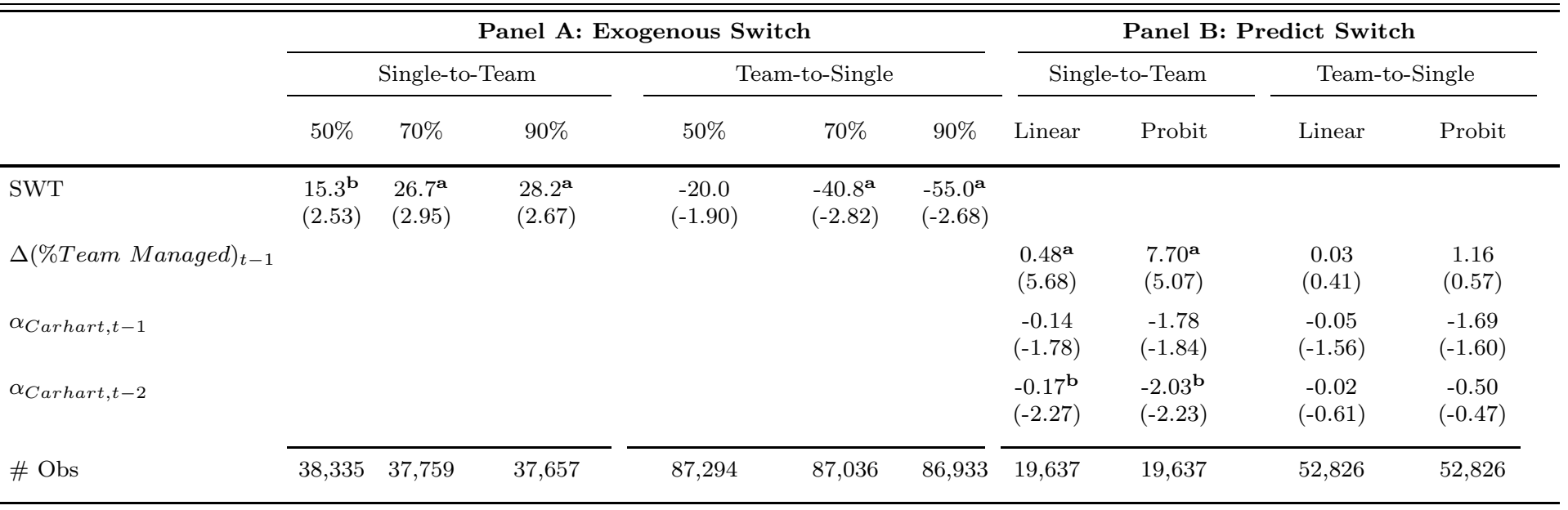

Panel C: Endogenous Switch

\begin{tabular}{|c|c|c|c|c|c|c|c|c|c|}
\hline \multicolumn{5}{|c|}{ Single-to-Team } & \multicolumn{5}{|c|}{ Team-to-Single } \\
\hline OLS & IV & Control Func & Probit Treat & Heckman & OLS & IV & Control Func & Probit Treat & Heckman \\
\hline \multirow[t]{2}{*}{$\begin{array}{c}0.50 \\
(0.13)\end{array}$} & $\begin{array}{c}13.2 \\
(1.63)\end{array}$ & $\begin{array}{c}13.2 \\
(1.63)\end{array}$ & $\begin{array}{l}20.8^{\mathbf{a}} \\
(2.87)\end{array}$ & $\begin{array}{l}20.8^{\mathbf{a}} \\
(2.62)\end{array}$ & $\begin{array}{l}13.3^{\mathbf{b}} \\
(2.47)\end{array}$ & $\begin{array}{c}18.3 \\
(1.25)\end{array}$ & $\begin{array}{c}18.3 \\
(1.25)\end{array}$ & $\begin{array}{c}12.7 \\
(1.02)\end{array}$ & $\begin{array}{c}12.7 \\
(1.04)\end{array}$ \\
\hline & & $\begin{array}{c}-17.4 \\
(-1.83)\end{array}$ & $\begin{array}{l}-0.07^{\mathrm{a}} \\
(-3.47)\end{array}$ & $\begin{array}{l}-14.0^{\mathbf{a}} \\
(-3.73)\end{array}$ & & & $\begin{array}{c}-5.94 \\
(-0.40)\end{array}$ & $\begin{array}{c}0.00 \\
(0.06)\end{array}$ & $\begin{array}{c}0.32 \\
(0.06)\end{array}$ \\
\hline 48,655 & 48,655 & 48,655 & 48,655 & 48,655 & 98,236 & 98,236 & 98,236 & 98,236 & 98,236 \\
\hline
\end{tabular}

